\title{
Immunolocalization of 7-2-Ribonucleoprotein in the Granular Component of the Nucleolus ${ }^{1}$
}

\author{
GEORG REIMER, ${ }^{*}$ IVAN RAŠKA, ${ }^{\dagger}$ ULRICH SCHEER, $₫$ and \\ ENG M. TAN $\$, 2$
}

*Department of Dermatology, University of Erlangen-Nürnberg, D-8520 Erlangen, Federal Republic of Germany; ${ }^{\dagger}$ Institute of Experimental Medicine, Čzechoslovak Academy of Sciences,

Prague, CSSR; $\ddagger$ Institute of Zoology I, University of Würzburg, D-8700 Würzburg, Federal Republic of Germany; and $\S$ W. M. Keck Autoimmune Disease Center, Scripps Clinic and Research Foundation, La Jolla, California 92037

\begin{abstract}
Certain autoimmune sera contain antibodies against a nucleolar ribonucleoprotein particle associated with 7-2-RNA (R. Reddy et al. (1983) J. Biol. Chem. 258, 1383; C. Hashimoto and J. A. Steitz (1983) J. Biol. Chem. 258, 1379). In this study, we showed by immunofluorescence microscopy that antibodies reactive with 7-2-ribonucleoprotein immunolocalized in the granular regions of actinomycin $\mathrm{D}$ and 5,6-dichloro-1- $\beta$-D-ribofuranosylbenzimidazole (DRB)—segregated nucleoli from Vero cells. By electron microscopic immunocytochemistry, antigen-antibody complexes were located in the granular component of transcriptionally active nucleoli from rat liver hepatocytes and HeLa cells. Anti-72-RNP antibodies from two autoimmune sera immunoprecipitated a major protein of $M_{\mathrm{r}}$ 40,000 from $\left[{ }^{35} \mathrm{~S}\right]$ methionine-labeled HeLa cell extract. The immunolocalization data suggest that 7-2-ribonucleoprotein may be involved in stages of ribosome biogenesis which take place in the granular component of the nucleolus, i.e., assembly, maturation, and/or transport of preribosomes. (c) 1988 Academic Press, Inc.
\end{abstract}

Patients with systemic autoimmune diseases frequently produce autoantibodies against a variety of nuclear and nucleolar proteins and RNA-protein complexes [3]. Recently, autoimmune sera were shown to be valuable tools in mapping the topology of nucleolar proteins (for review, see Ref. [4]). We showed that certain scleroderma antibodies stain the fibrillar centers of nucleoli and are directed against RNA polymerase I [5]. Other scleroderma sera contain antibodies against a basic ( $\mathrm{p} I, 8.5) M_{\mathrm{r}} 34,000$ nucleolar protein of the U3-ribonucleoprotein complex [6]. This protein was located in the fibrillar component of nucleoli [7] and hence named fibrillarin. Since various stages of ribosome biogenesis in eukaryotes are believed to take place in morphologically defined regions of nucleoli (for review see Ref. [8]), immunolocalization of any nucleolar protein should provide important leads for understanding the functional organization of the nucleolus.

In this study autoantibodies against 7-2-ribonucleoprotein were located within the granular component of nucleoli. This specific localization indicates that 7-2ribonucleoprotein may be involved in preribosome assembly, maturation, and/or

\footnotetext{
${ }^{1}$ This is publication number 4789 BCR of the Department of Basic and Clinical Research, Scripps Clinic and Research Foundation, La Jolla, California 92037. This work was supported by NIH Grant AM32063. G. Reimer was supported by a grant of the Deutsche Forschungsgemeinschaft.

${ }^{2}$ To whom reprint requests should be addressed at Scripps Clinic and Research Foundation, 10666 North Torrey Pines Road, La Jolla, CA 92037.

${ }^{3}$ Abbreviations used: PBS, phosphate-buffered saline; RNP, ribonucleoprotein; DRB, 5,6-dichloro-1- $\beta$-D-ribofuranosylbenzimidazole; mol wt, molecular weight.
} 
transport, biological stages of ribosome biogenesis that have been mapped to the granular component of the nucleolus (for review, see Ref. [8]). Identification and characterization of autoantigens may also be important steps in the elucidation of the nature of autoimmune responses in defined disease entities.

\section{MATERIAL AND METHODS}

Antibodies. Reference antibodies To against 7-2-ribonucleoprotein were from the same serum as that used by Reddy et al. [1]. Serum Wa was from a 48-year-old female patient with a 6-year history of relapsing arthritis/arthralgias, moderate lymphocytopenia, fever, malaise, and severe Raynaud's phenomenon without further clinical or laboratory findings which would allow definite classification of her connective tissue disease. Normal human serum and anti-SS-B/La serum were from the serum collection of the Autoimmune Disease Center, Scripps Clinic and Research Foundation, La Jolla, California. Monoclonal antibody 72B9 of the IgG2a isotype reactive with U3-RNP-associated fibrillarin was derived from spleen cells of a NZB/NZW F1 mouse by hybridoma technology [9].

Indirect immunofluorescence. Indirect immunofluorescence was performed with human $\mathrm{HeLa}$ cells, monkey Vero cells, marsupial rat kangaroo PtK2 cells, and fish FHM cells. The cells were obtained from the American Type Culture Collection (Rockville, MD). Cells were grown on microscopic slides and fixed in acetone/methanol $3: 1$ cooled to $-20^{\circ} \mathrm{C}$ for $3 \mathrm{~min}$. Other substrates were commercially available human Hep-2 cells (Bion, Park Ridge, IL) and rabbit kidney cells (Electronucleonics, Bethesda, MD). Autoimmune and control sera were diluted at $1: 40$ in phosphate-buffered saline (PBS), ${ }^{3} \mathrm{pH}$ 7.4. As detecting reagents, a fluorescein-labeled (Behring Diagnostics, La Jolla, CA) and a rhodamine-labeled (Tago, Burlingame, CA) goat anti-human IgG conjugate were used. A fluorescein-labeled goat anti-mouse IgG conjugate was obtained from Tago. Intensity of immunofluorescence staining was graded from weak $(+)$, moderate $(++)$, to strong $(+++)$. Results were read on a Leitz Ortholux II fluorescence microscope equipped with a Leitz Ploempak vertical illuminator using a NPL Fluortar 100/1.32 oil immersion objective. Double-label immunofluorescence was performed as described [10].

Drug studies. Segregation of nucleoli in tissue culture Vero cells into fibrillar and granular regions was induced by the addition $0.2 \mu \mathrm{g} / \mathrm{ml}$ actinomycin D to the culture medium for $4 \mathrm{~h}$ or $50 \mu \mathrm{g} / \mathrm{ml} 5,6$ dichloro-1- $\beta$-D-ribofuranosylbenzimidazole, a halogenated adenosine analog, for $6 \mathrm{~h}$. Both drugs were purchased from Behring Diagnostics. After drug treatment, cells were fixed in acetone/methanol 3:1 and processed for indirect immunofluorescence as described above.

Electron microscopic immunocytochemistry. For preembedding antibody labeling, frozen sections ( $5 \mu \mathrm{m}$ thickness) of rat liver were fixed in acetone at $-20^{\circ} \mathrm{C}$ for $10 \mathrm{~min}$, air dried, and incubated with normal control serum, scleroderma anti-RNA polymerase I, serum To, or serum Wa diluted $1: 100$ in PBS for $30 \mathrm{~min}$. After several washes in PBS, goat IgG (1 mg/ml in PBS) was added to the tissue sections for 5 min to block nonspecific binding sites followed by goat anti-human IgG coupled to colloidal gold (5 nm diameter, Janssen Life Sciences, Beerse, Belgium) diluted 1:20 in PBS and containing $1 \mathrm{mg} / \mathrm{ml}$ goat IgG. After $2 \mathrm{~h}$ incubation at $4^{\circ} \mathrm{C}$, the specimens were fixed and processed for electron microscopy as described recently [11]. For postembedding antibody labeling, HeLa cells were fixed for $2 \mathrm{~h}$ in $8 \%$ paraformaldehyde containing $0.2 \mathrm{M}$ pipes buffer, $\mathrm{pH} \mathrm{7.0.} \mathrm{The} \mathrm{cell} \mathrm{pellet} \mathrm{was}$ infused with 2.1 M sucrose in PBS and frozen on cryospecimen pins. Ultrathin frozen sections were cut on a Reichert Ultracut microtome equipped with FC4 cryoattachment. Cryosections were incubated with To antibodies diluted 1:10 in PBS for $1 \mathrm{~h}$. Secondary antibodies specific for human IgG coupled to $10-\mathrm{nm}$ gold particles (Janssen Life Sciences) were used as the detecting reagent and the immunoreaction was visualized as described in detail elsewhere [12-13]. Grids with Formvar-carbon films were inspected in Opton 92S, Philips 301, and Jeol 1200 electron microscopes.

Nuclease digestion. For nuclease digestion experiments, Vero cells grown on microscopic slides were digested with $0.25 \mathrm{mg} / \mathrm{ml}$ DNase I (Millipore, Freehold, NJ) in PBS containing $5 \mathrm{mM} \mathrm{MgCl}_{2}$, or with $0.25 \mathrm{mg} / \mathrm{ml}$ RNase A (Millipore) in PBS for $30 \mathrm{~min}$ at $37^{\circ} \mathrm{C}$. Phenylmethylsulfonyl fluoride at 2 $\mathrm{m} M$ was added to the digestion buffers to prevent proteolytic degradation. After digestion, cells were washed in PBS and further processed for indirect immunofluorescence as described. As controls, substrates were also preincubated in buffer without enzymes. To assess the effectiveness of nuclease digestion, monoclonal antibodies to native DNA [10] and RNA [14] were simultaneously incubated with nuclease-pretreated cells and processed by immunofluorescence.

Immunoprecipitation. HeLa cells were cultured in monolayers and were radiolabeled for $20 \mathrm{~h}$ with $\left[{ }^{35} \mathrm{~S}\right]$ methionine and $\left[{ }^{32} \mathrm{P}\right]$ orthophosphate (New England Nuclear, Boston, MA). Cells were extracted 
in buffer A containing $10 \mathrm{~m} M$ Tris- $\mathrm{HCl}$ ( $\mathrm{pH}$ 7.4), $150 \mathrm{mM} \mathrm{NaCl}, 1.5 \mathrm{mM} \mathrm{MgCl} 2,0.5 \%$ Nonidet-P40, supplemented with Kallikrein inactivator (Behring Diagnostics) as described [15]. Immunoprecipitation of radiolabeled antigens was performed as described [5, 15]. In brief, serum aliquots were incubated with protein A-Sepharose CL-4B (Pharmacia, Uppsala, Sweden) at 10\% (v/v) suspended in buffer B (50 mM Tris- $\mathrm{HCl}$ (pH 7.4), $150 \mathrm{mM} \mathrm{NaCl}, 5 \mathrm{mM}$ EDTA, $0.5 \%$ sodium deoxycholate, and $0.1 \%$ sodium dodecyl sulfate (SDS)). After washing in buffer B, radiolabeled HeLa cell proteins were added to the beads and incubated for $1 \mathrm{~h}$ with constant mixing. The beads were then washed in buffer B containing $23 \mathrm{U} / \mathrm{ml}$ Kallikrein inactivator and the proteins were detached from the beads by boiling in Laemmli sample buffer [16]. Antigen analysis was performed in 15 and 17.5\% SDS-polyacrylamide gels followed by autoradiography. Half of the ${ }^{32} \mathrm{P}$-labeled pellet was phenol-extracted and any RNA was precipitated in ethanol. RNA analysis was performed in $7 M$ urea, $8 \%$ polyacrylamide gels.

Antigen depletion experiments were performed as described [5]. $\left.{ }^{35} \mathrm{~S}\right]$ methionine-labeled HeLa cell extract $(50 \mu \mathrm{g}$ of protein) was preabsorbed with $\operatorname{IgG}(20 \mu \mathrm{g})$ from serum To bound to protein A-Sepharose CL-4B for $45 \mathrm{~min}$ at $4^{\circ} \mathrm{C}$. The supernatant was then used for immunoprecipitation with the same amount of IgG from serum Wa. In another experiment, $\left[{ }^{35} \mathrm{~S}\right]$ methionine-labeled HeLa cell proteins were digested with RNase at $0.25 \mathrm{mg} / \mathrm{ml}$ and then preabsorbed with IgG from serum Wa. The absorbed supernatant was then used as antigen source in immunoprecipitation with serum To.

\section{RESULTS}

Indirect immunofluorescence. Autoimmune serum To produced bright homogeneous staining $(+++)$ of all nucleoli in Hep-2 cells, HeLa cells, and Vero cells. Weak $(+)$ nucleoplasmic staining was also observed. Nucleolar staining (+ to $++)$ was also present in rat kangaroo PtK2 and fish FHM cells. Figure 1 shows nucleolar staining by antibodies from serum To in HeLa cells $(a)$ and Vero cells (c). For comparison, all cells are also shown in phase-contrast optics ( $b$ and $d)$.

For immunolocalization of autoantibodies from serum To in nucleolar subcompartments, Vero cells were exposed to the nucleolus-segregating drugs actinomycin D and DRB. Following drug treatment, cells were processed for indirect immunofluorescence. Actinomycin D-inactivated nucleoli show a typical segregation of the fibrillar component from the granular component, resulting in the formation of distinct nucleolar hemispheres [17-19] as shown by phase-contrast microscopy in Fig. $2 a$. The dark hemispheres (arrows) in $(a)$ represent the granular regions. Antibodies from serum To were now detected in the granular regions with a rhodamine anti-human IgG conjugate $(b)$. By contrast, mouse monoclonal antibody 72B9 against fibrillarin stained the fibrillar component (c) of the same segregated nucleoli as shown with a fluorescein anti-mouse IgG conjugate. When DRB was added to Vero cells growing in culture, the compact nucleoli of Vero cells unraveled into extended beaded strands again segregating the nucleolus into granular and fibrillar regions [20-22]. The phase dark granular regions in $(d)$ are pointed out by arrows. Immunofluorescence staining of DRBpretreated Vero cells by antibodies from serum To was in the granular regions $(e)$ whereas monoclonal antibody $72 \mathrm{~B} 9$ stained the fibrillar regions of DRB-segregated nucleoli in a "necklace" distribution $(f)$. It should be noted that actinomycin D and DRB, in concentrations and incubation periods as used in this study, reduced staining of segregated nucleoli when compared with the staining intensity of untreated cells (for comparison see Fig. 1).

Antibodies from serum Wa gave identical nucleolar immunofluorescence re- 

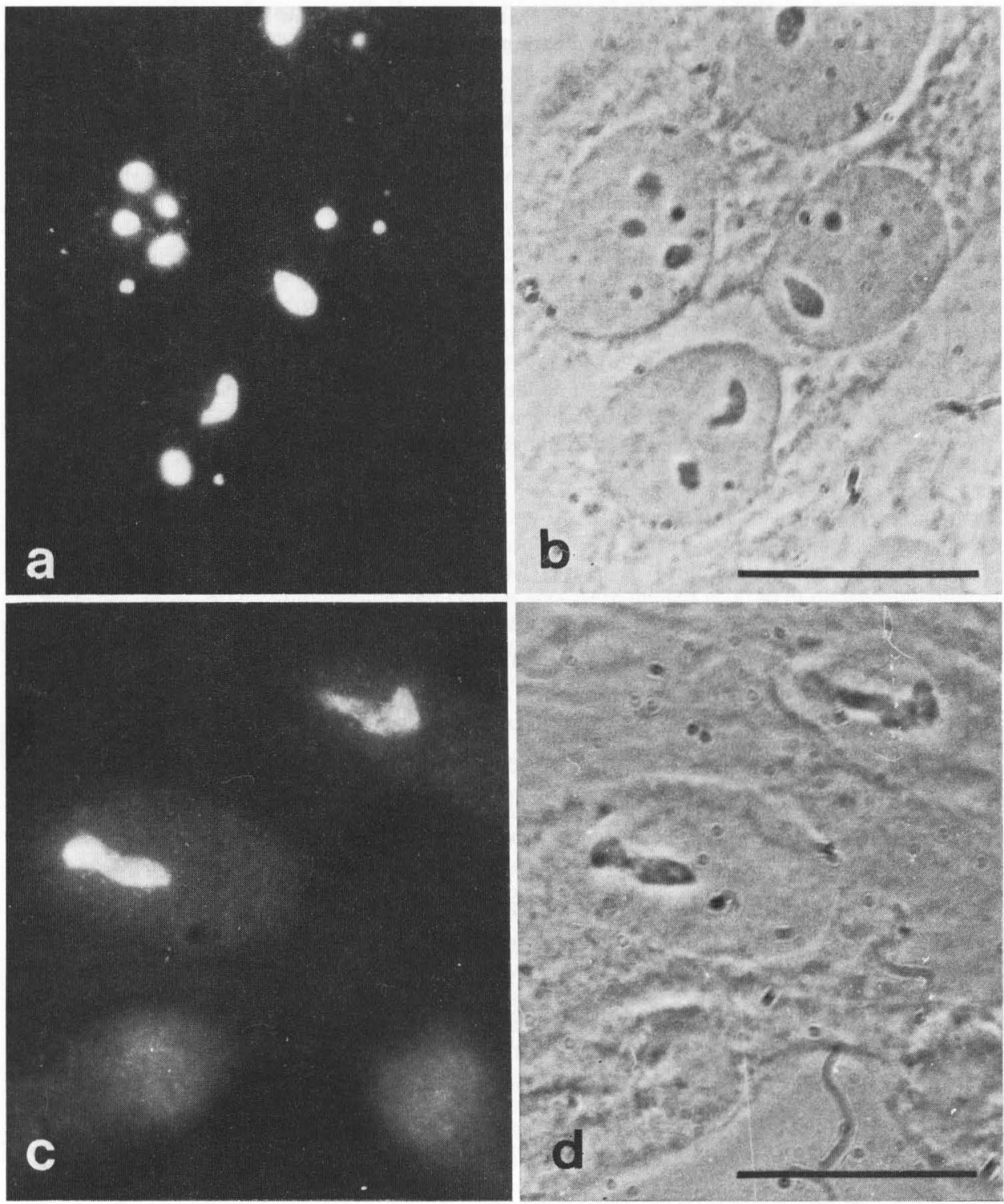

Fig. 1. Staining patterns produced by antibodies from serum To reactive with 7-2-ribonucleoprotein in tissue culture HeLa and Vero cells. After incubation of the cells with serum To, antibody-antigen complexes were detected by a fluorescein anti-human $\operatorname{IgG}$ conjugate. Bright homogeneous nucleolar staining was present in all HeLa cells $(a)$ and Vero cells. Weak granular nucleoplasmic staining was also produced by serum To. In Vero cells during late telophase $(c)$ immunofluorescence was diffusely distributed in the reconstituting nuclei with little staining of reforming nucleolar structures. All cells are also shown in phase-contrast optics $(b$ and $d)$. Bars $10 \mu \mathrm{m}, \times 1450$.

sults in untreated as well as actinomycin D- or DRB-treated Vero cells (not shown).

Electron Microscopy. Electron microscopic immunocytochemistry was performed using serum To, Wa, and different control sera in the pre- and postembed- 

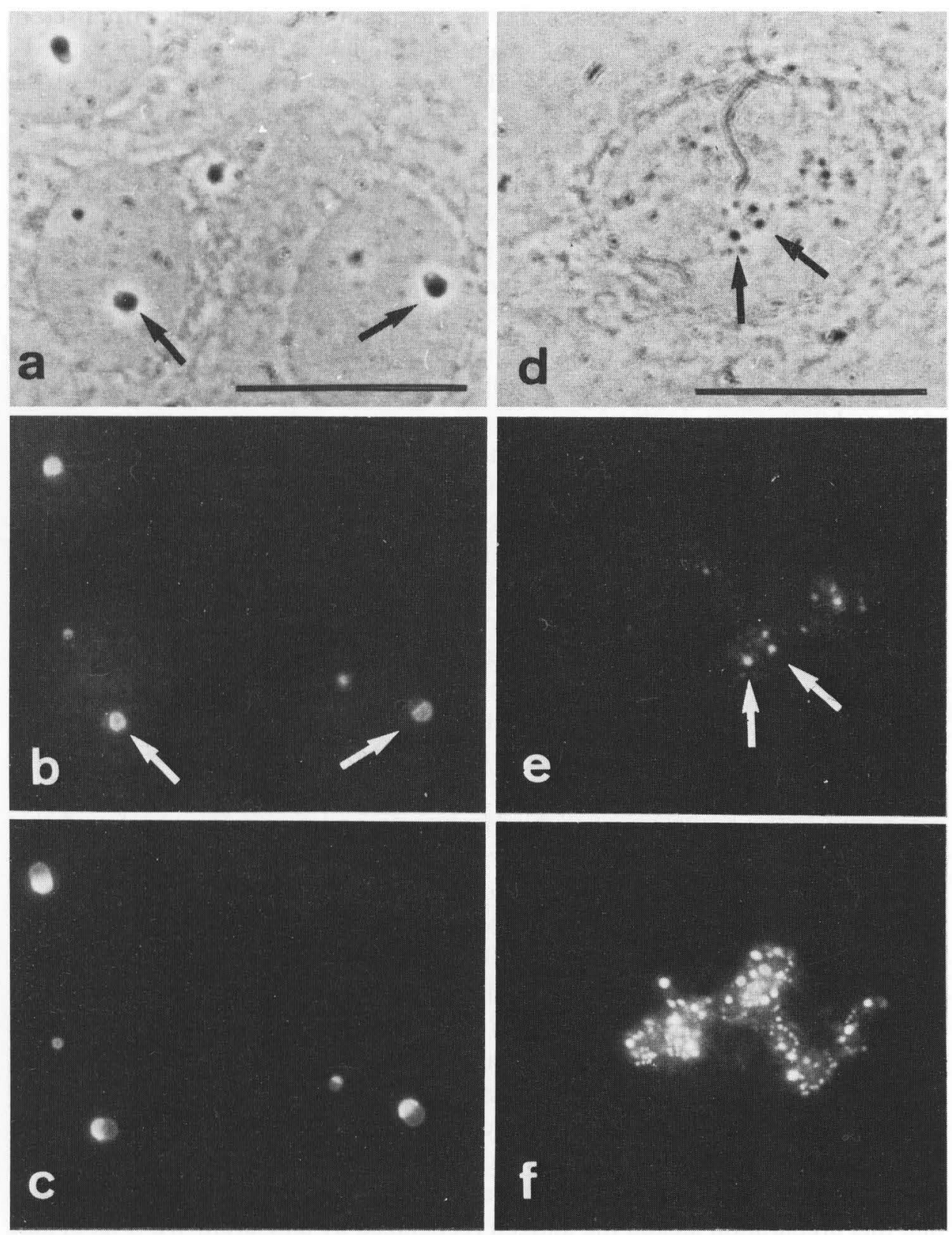

Fig. 2. Drug studies. Tissue culture Vero cells were exposed to actinomycin D $(a, b$, and $c)$ and DRB $(d, e$, and $f)$ before processing for indirect immunofluorescence in the doublelabel technique. The granular component in actinomycin D $(a)$ and DRB-segregated nucleoli $(d)$ is the phase denser portion (arrows) of the segregated nucleoli. Antibodies from serum To predominantly stained the granular component of actinomycin D $(b)$ and DRB-segregated nucleoli $(e)$. As a control, the fibrillar component ( $c$ and $f$ ) was specifically stained by monoclonal antibody 72B9 against fibrillarin, a U3RNP-associated protein. Bars $10 \mu \mathrm{m}, \times 1450$. 
ding immunogold label techniques. In these experiments, antibodies from serum To and Wa were localized in the granular component of nucleoli in rat liver hepatocytes and HeLa cells. Fig. 3 illustrates the results of the preembedding labeling technique and shows that IgG from serum To was selectively enriched over the granular component and virtually absent from the dense fibrillar component or fibrillar centers. Using ultrathin frozen sections of HeLa cells and serum To for the postembedding labeling protocol, gold-antibody-antigen complexes were again localized predominantly over the granular component and essentially absent from the dense fibrillar component or fibrillar centers (Fig. 4). In the control experiments, scleroderma anti-RNA polymerase I antibodies were selectively enriched over the fibrillar centers in both labeling techniques and virtually absent from the granular or dense fibrillar components (not shown, also see Refs. $[4,5$, and 23]). Thus, both labeling techniques gave comparable results.

Nuclease digestion studies. To evaluate the effect of nuclease digestion on the antigen recognized by antibodies from serum To and Wa, Vero cell substrates were preincubated with DNase and RNase. Neither of these nucleases substantially altered intensity of nucleolar immunofluorescence staining when compared with the controls in which buffers without enzymes were used (not shown). By contrast, nuclear staining by monoclonal antibody against native DNA [10] was abolished by DNase pretreatment of cell substrates. Digestion of substrates with RNase was also complete. This was shown by loss of nucleolar and cytoplasmic staining produced by a monoclonal antibody that binds to ribosomal RNA [14]. These data suggested that the antigenicity of 7-2-ribonucleoprotein is not dependent on the RNA moiety or DNA but rather located in the protein which is in agreement with results obtained by Hashimoto and Steitz [2] who found that deproteinized RNA itself is not the target.

Immunoprecipitation. By screening of a large number of antinucleolar autoimmune sera, one serum (Wa) precipitated a $M_{\mathrm{r}} 40,000$ protein from $\left[{ }^{35}\right.$ S $]$ methionine-labeled $\mathrm{HeLa}$ cell extract. The ${ }^{32} \mathrm{P}$-labeled immunoprecipitate obtained by this serum contained RNA with the mobility as expected for 7-2-RNA but no other RNA species (see Fig. 6, lanes 3 and 5). To determine whether serum Wa shared the specificity of serum To with regard to its reactivity with 7-2-RNP and might be the better antibody for further characterization of the composition of 72-RNP (since lacking 8-2-RNP specificity; see Discussion), we absorbed ${ }^{35}$ S $]$ methionine-labeled HeLa cell extract with the IgG fraction of serum To. We then used this absorbed extract in an immunoprecipitation assay and showed that this preparation lacked the antigen recognized by antiserum Wa (Fig. 5, lane 4). Note that antibodies from serum To precipitated a $M_{\mathrm{r}} 40,000$ protein (arrow in lane 3). In a reciprocal fashion, radiolabeled HeLa cell extract, which this time had been digested with RNase, was absorbed with IgG from serum Wa and used in immunoprecipitation to show that the antigen precipitated by serum To was absent in the immunoprecipitate (lane 7). Lanes 2 and 5 show the immunoprecipitates obtained with normal human serum whereas lane $l$ shows ${ }^{14} \mathrm{C}$-labeled molecular weight markers. Figure 6, lane 2, again shows a $M_{\mathrm{r}} 40,000$ polypeptide (arrowhead) precipitated by antibodies from serum Wa. This protein was not 


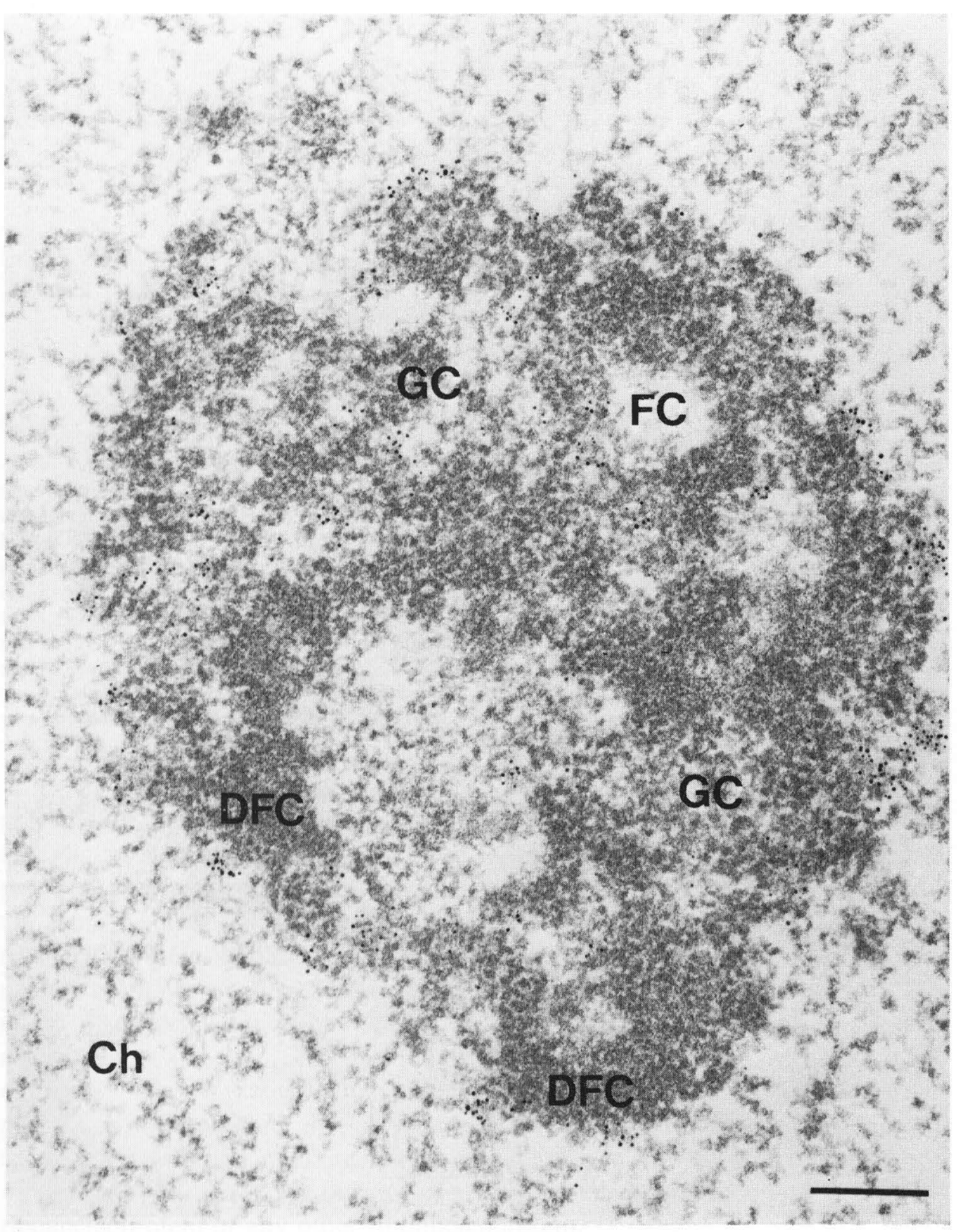

Fig. 3. Electron microscopic localization of 7-2-ribonucleoprotein using the preembedding immunogold label technique. Sections of rat liver were incubated with serum To followed by secondary antibodies coupled to 5 -nm gold particles. IgG from serum To bound to the granular component (GC) of the nucleolus. The dense fibrillar component (DFC) and the fibrillar centers (FC) are virtually free of gold particles. Ch, chromatin surrounding the nucleolus. Bar $0.2 \mu \mathrm{m}, \times 75,000$. 


\section{Reimer et al.}

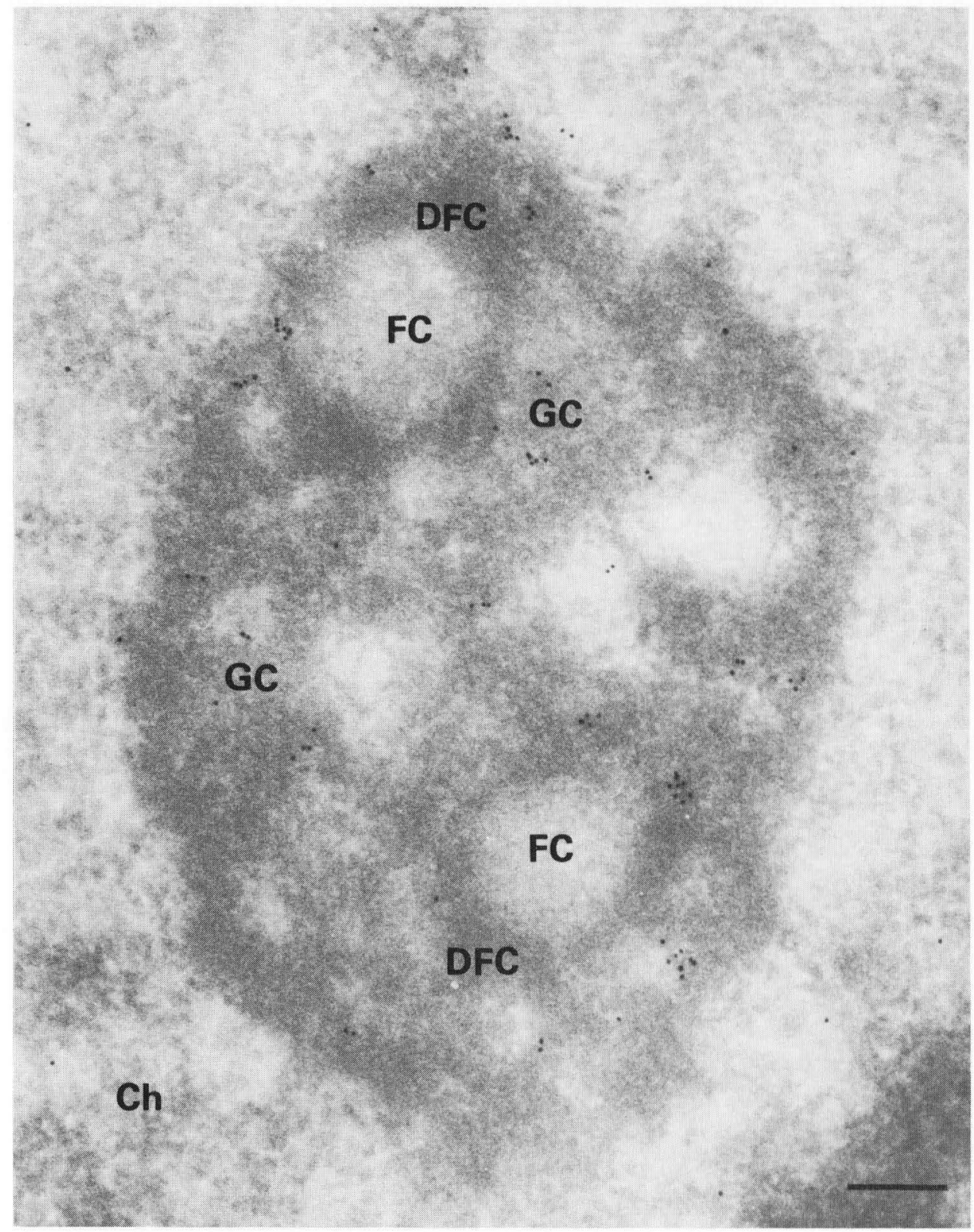

Fig. 4. Electron microscopic localization of 7-2-ribonucleoprotein using the postembedding immuno-gold label technique. Ultrathin frozen sections of paraformaldehyde-fixed HeLa cells were incubated with serum To and the immunoreaction was visualized by a second incubation with antihuman IgG antibodies coupled to 10 -nm colloidal gold particles. Gold particles representing antibody-antigen complexes are almost exclusively present over the granular component (GC) and virtually absent from the fibrillar centers (FC) or the dense fibrillar component (DFC). Bar $0.2 \mu \mathrm{m}, \times 67,500$. 


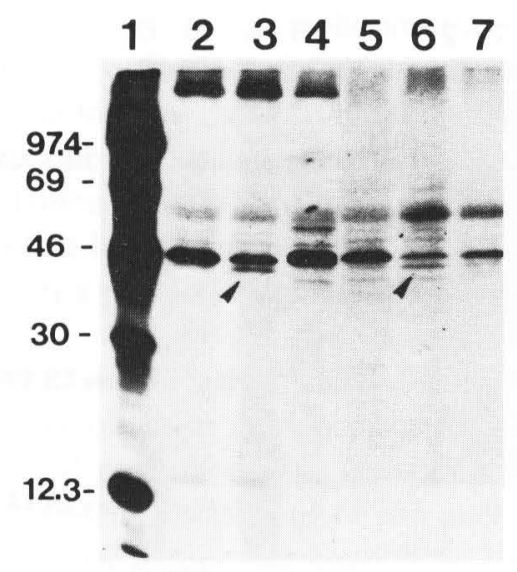

Fig. 5. Immunoabsorption experiments. Autoradiogram of $\left[{ }^{35} \mathrm{~S}\right]$ methionine-labeled immunoprecipitates from HeLa cell extract resolved on a $17.5 \%$ SDS-polyacrylamide gel. Lanes 2 to 4, immunoprecipitates from undigested HeLa cell extract, lanes 5 to 7 from RNase-digested extract. Lane 1 , ${ }^{14} \mathrm{C}$ labeled molecular weight markers (overexposed). Lane 2, proteins precipitated by normal human serum. Lane 3, a $M_{\mathrm{r}} 40,000$ protein (arrow) is additionally precipitated by To antibodies from $\mathrm{HeLa}$ cell extract. Lane 4 , proteins immunoprecipitated by antibodies from serum Wa using the antigen extract absorbed with To antibodies. Lane 5, normal human serum. Lane 6 , a $M_{\mathrm{r}} 40,000$ protein is precipitated by Wa antibodies. Lane 7, immunoprecipitate obtained by To antibodies with the extract preabsorbed with Wa antibodies. The $M_{\mathrm{r}} 40,000$ protein precipitated by antibodies from serum To (lane 3 ) is not present in lane 7 . Note that antibodies from normal human serum and the autoimmune sera nonspecifically precipitate a $M_{\mathrm{r}} 46,000$ protein (probably actin).

precipitated by autoimmune antinucleolar sera with different immunological specificities such as anti-RNA polymerase I [5] or anti-PM-Scl [24]. The particle precipitated by antibodies from serum Wa contained RNA (Fig. 6, lane 3) with the same mobility as that reported for 7-2-RNA associated with the SS-B/La ribonucleoprotein [2] (Fig. 6, lane 4). Lane 4 also contains the $\left[{ }^{32} \mathrm{P}\right]$ orthophosphate-labeled pre-5S, pre-tRNA, and a $M_{\mathrm{r}} 46,000$ phosphoprotein. Lanes 5 and 6 of this figure display the RNA species of the SS-B/La ribonucleoprotein particle after phenol-extraction and ethanol-precipitation side by side with the RNA coprecipitated by antibodies from serum Wa after electrophoresis in $7 \mathrm{M}$ urea $8 \%$ polyacrylamide gel. Note that only one RNA species with the mobility expected for 7-2-RNA was present in the immunoprecipitates of anti-Wa antibodies (lane 5) suggesting that serum Wa did not contain antibodies against cytoplasmic 8-2ribonucleoprotein or any other ribonucleoprotein.

Immunoblotting with extractable HeLa cell proteins and isolated HeLa cell nucleoli as antigen source did not identify a $M_{\mathrm{r}} 40,000$ protein as the antigenic target although several weak bands with higher molecular weights were observed on prolonged exposure.

\section{DISCUSSION}

A ribonucleoprotein particle complexed with 7-2-RNA was recently precipitated by two different autoimmune sera designated anti-To and anti-Th by Reddy et 


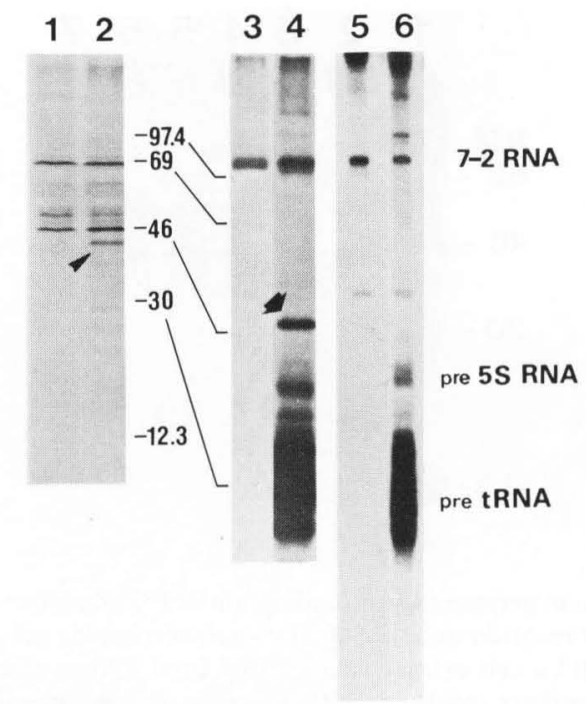

Fig. 6. Immunoprecipitation of $\left[{ }^{35} \mathrm{~S}\right]$ methionine-labeled HeLa cell proteins (lanes $l$ and 2 ) and $\left[{ }^{32} \mathrm{P}\right]$ orthophosphate-labeled HeLa cell RNA-protein complexes (lanes 3 and 4) with different autoimmune sera. Immunoprecipitates were electrophoretically resolved in $17.5 \%$ (lanes 1 and 2 ) and $15 \%$ (lanes 3 and 4) SDS-polyacrylamide gels. The ${ }^{32} \mathrm{P}$-labeled immunoprecipitates were also phenolextracted and any RNA was ethanol-precipitated and resolved in $7 M$ urea $8 \%$ polyacrylamide gels (lanes 5 and 6). Lane 1 represents results by normal control serum; lanes 2, 3, and 5 by serum Wa. Lanes 4 and 6 show the antigen precipitated by anti-SS-B/La antibodies. Antibodies from serum Wa precipitated a $M_{\mathrm{r}} 40,000$ protein (arrow, lane 2) which was not precipitated by normal human serum antibodies (lane 1 ). This $M_{\mathrm{r}} 40,000$ protein did not label with $\left[{ }^{32} \mathrm{P}\right]$ orthophosphate nor any other proteins (lane 3). By contrast, anti-SS-B/La antibodies precipitated a $M_{\mathrm{r}} 46,000$ phosphoprotein (arrow) as shown in lane 4 . The RNA coprecipitated by antibodies from serum Wa (lanes 3 and 5) has the same mobility as the presumptive 7-2-RNA species precipitated by anti-SS-B/La antibodies (lanes 4 and 6).

al. [1] and Hashimoto and Steitz [2], respectively. Serum To was from a patient with scleroderma and serum Th was from a patient with systemic lupus erythematosus. 7-2-RNA was originally characterized as a nucleolar RNA species in biochemical fractionation experiments on rat cells [25] and was shown to be among RNA polymerase III transcripts [2]. Antibodies from serum To also precipitated a $7-2 *$-RNA species which had a slightly lower electrophoretic mobility on polyacrylamide gels than 7-2-RNA. It was suggested that this difference in mobility might reflect a few additional nucleotides on the $3^{\prime}$-end of the 7$2 *$-RNA molecule [2]. This 7-2*-RNA species appears to be a precursor of 7-2RNA and was also shown to be brought down by anti-SS-B/La antibodies [2]. In addition to precipitating 7-2-RNA and 7-2*-RNA, antibodies from serum To and Th also precipitated cytoplasmic 8-2-RNA. It was clearly shown that bound protein was required for antigenicity of both 7-2- and 8-2- ribonucleoprotein [2]. The exact molecular composition and biological function of 7-2-ribonucleoprotein, however, are unknown.

In the present study, we showed that autoantibodies against 7-2-RNP immunoprecipitated at least one protein labeled with $\left[{ }^{35} \mathrm{~S}\right]$ methionine from a HeLa cell 
extract with mol wt $\left(M_{\mathrm{r}}\right)$ of 40,000 . No phosphoproteins could be detected in the immunoprecipitates using $\left[{ }^{32} \mathrm{P}\right]$ orthophosphate-labeled HeLa cell extract as antigen source. It is conceivable that the $M_{\mathrm{r}} 40,000$ protein is the only protein associated with 7-2-RNA although additional experimental evidence is needed to support this conclusion. Unfortunately, the antibodies did not react unequivocally with a specific polypeptide band in immunoblots, an observation also made by Hashimoto and Steitz [2] in a previous investigation with autoantibodies against 7-2-RNP.

The 7-2-ribonucleoprotein was clearly localized in the granular component of transcriptionally active nucleoli from rat liver hepatocytes and HeLa cells, as shown by preembedding and postembedding immunogold electron microscopy. This localization to the granular component of the nucleolus was confirmed by immunofluorescence microscopy after segregation of Vero cell nucleoli by the drugs actinomycin D and DRB. The staining intensity of the granular component of the segregated nucleoli was reduced by drug treatment as compared with untreated nucleoli. The reduced staining parallels findings obtained with a novel myositis/scleroderma antigen named PM-Scl [24]. The PM-Scl antigen was even more sensitive to actinomycin D and DRB than 7-2-RNP, and, therefore, we postulated a possible relationship of the PM-Scl antigen with preribosomal particles.

The epitopes recognized by antibodies against 7-2-ribonucleoprotein are remarkably conserved during evolution since the epitopes were present in nucleoli of cells from different species. Interestingly, the epitopes of other antinucleolar autoantibodies such as anti-RNA polymerase I [5], anti-PM-Scl [24], and antifibrillarin [11] were also shown to be well conserved during evolution suggesting that they are basic and important structures of nucleolar proteins.

There are several nucleolar proteins which have been identified and localized in the granular component of the nucleolus. Recently, Hügle et al. [26] identified a nuclear/nucleolar $M_{\mathrm{r}} 40,000$ protein in Xenopus laevis and other amphibia which appears to be specific to precursor particles of the large ribosomal subunit. This protein, which was named ribocharin, was specifically mapped to the granular component of the nucleolus and nucleoplasmic $65 \mathrm{~S}$ particles in amphibia. Ribosomal protein S1, the most acidic protein of the small ribosomal subunit, was identified by a monoclonal antibody and localized in the granular component of the nucleolus [27]. Another nucleolar protein B23 of rat hepatoma and rat liver cells (for review, see Ref. [28]) with a $M_{\mathrm{r}}$ value of 37,000 was also mainly localized in the granular component of the nucleolus [29-31]. Protein B23 is believed to be associated with ribosomal precursor particles [30]. Whether ribocharin and protein B23 are related is not known. Although the present observations are preliminary, it is of interest to note that the proteins precipitated by serum To and serum Wa have a molecular weight similar to those of ribocharin and B23. However, an association of the latter two nucleolar proteins with small nucleolar RNAs has not been reported so far. It remains unknown whether ribocharin or protein B23 are related to 7-2-RNP as detected by human autoantibodies. 
In situ mapping of nucleolar proteins to defined structural components of nucleoli may be important for understanding their function. Autoantibodies reactive with 7-2-ribonucleoprotein clearly localize in the granular component of the nucleolus. It is tempting to suggest that 7-2-ribonucleoprotein may be involved in the assembly of ribosomal precursor particles, their maturation, and/or transport, stages of ribosome biogenesis that have been mapped to the granular component of the nucleolus. Further studies are needed to advance this hypothesis and antibodies from autoimmune sera such as serum Wa or To could be helpful tools in carrying out such investigations.

\section{REFERENCES}

1. Reddy, R., Tan, E. M., Henning, D., Nogha, K., and Busch, H. (1983) J. Biol. Chem. $258,1383$.

2. Hashimoto, C., and Steitz, J. A. (1983) J. Biol. Chem. 258, 1379.

3. Tan, E. M. (1982) Adv. Immunol. 33, 167.

4. Reimer, G., Raska, I., Tan, E. M., and Scheer, U. (1987) Virchow's Arch. B, 54, 131.

5. Reimer, G., Rose, K. M., Scheer, U., and Tan, E. M. (1987) J. Clin. Invest. 79, 65.

6. Lischwe, M. A., Reddy, R., Ochs, R. L., Yeoman, L. C., Tan, E. M., Reichlin, M., and Busch, H. (1985) J. Biol. Chem. 260, 14304.

7. Ochs, R. L., Lischwe, M. A., Spohn, W. H., and Busch, H. (1985) Biol. Cell 54, 123.

8. Hadjiolov, A. A. (1985) The Nucleolus and Ribosome Biogenesis. Springer Verlag, Berlin.

9. Reimer, G., Pollard, K. M., Penning, C. A., Ochs, R. L., Lischwe, M. A., Busch, H., and Tan, E. M. (1987) Arthritis Rheum. 30, 793.

10. Reimer, G., Rubin, R. L., Kotzin, B. L., and Tan, E. M. (1984) J. Immunol. 133, 2532.

11. Scheer, U., and Rose, K. M. (1984) Proc. Natl. Acad. Sci. USA 81, 1431.

12. Tokuyasu, K. T. (1980) Histochem. J. 12, 381.

13. Griffiths, G., McDowall, A., Back, R., and Dubochet, J. (1984) J. Ultrastruct. Res, 89, 65.

14. Reimer, G., Totoritis, M. C., Rubin, R. L., Theophilopoulos, A. N., and Tan, E. M. (1986) Arthritis Rheum. 29, S74.

15. Francoeur, A. M., and Mathews, M. B. (1982) Proc. Natl. Acad. Sci. USA 79, 6772.

16. Laemmli, U. K. (1970) Nature (London) 227, 680.

17. Busch, H., and Smetana, K. (1970) The Nucleolus. Academic Press, New York.

18. Bernard, W. (1971) in Advances in Cytopharmacology (F. Clementini and B. Ceccarelli. Eds.), Raven Press, New York.

19. Simard, R., Langelier, Y., Mandeville, R., Maestracci, N., and Royal, A. (1974) The Cell Nucleus (H. Busch, Ed.), Academic Press, New York.

20. Granick, D. (1975) J. Cell Biol. 65, 398.

21. Granick, D. (1975) J. Cell Biol. 65, 418.

22. Scheer, U., Hügle, B., Hazan, R., and Rose K. M. (1984) J. Cell Biol. 99, 672.

23. Scheer, U., and Raska, I. (1987) Chromosomes Today 9, 284.

24. Reimer, G., Scheer, U., Peters, J.-M., and Tan, E. M. (1986) J. Immunol. 137, 3802.

25. Reddy, R., Li, W.-Y., Henning, D., Choi, Y. C., Nogha, K., and Busch, H. (1981) J. Biol. Chem. 256, 8452 .

26. Hügle, B., Scheer, U., and Franke, W. W. (1985) Cell 41, 615.

27. Hügle, B., Hazan, R., Scheer, U., and Franke, W. W. (1985) J. Cell Biol. 100, 873.

28. Busch, H. (1984) in Chromosomal Nonhistone Proteins, IV. Structural Associations (L.S. Hnilica, Ed.), CRC Press, Boca Raton, FL.

29. Daskal, Y., Smetana, K., and Busch, H. (1980) Exp. Cell Res. 127, 285.

30. Ochs, R. L., Lischwe, M. A., O'Leary, P., and Busch, H. (1983) Exp. Cell Res. 146, 139.

31. Spector, D. L., Ochs, R. L., and Busch, H. (1984) Chromosoma (Berlin) 90, 139. 